\title{
El Título "Deseos" en la Obra de Marina Mayoral
}

\author{
M. José Rodríguez Campillo* \\ Universitat Rovira i Virgili, Tarragona, Spain
}

\begin{abstract}
The human communication process is characterized by the set of rational activities that are carried out and that allow us to not only get information from the environment through perception but to infer new knowledge from already acquired. According to Relevance Theory, from the time we receive a linguistic ostensive stimulus, the recipient's mind starts automatically different types of processes, starting with the most mechanical decoding (grammatical process) and followed by other inferential nature, since the disambiguation and assignment relating to the identification of the sender's intention (pragmatic process): understanding a sentence or a text depends not only on the meaning of their surface structure but its inner meaning, of what implicit, in short. Similarly, when we read a novel, see a film or contemplate an event, according to Cognitive Principle of Relevance (PCR), the human mind maximizes relevance, ie in the overall process of understanding, "select" those items most relevant, those who follow the path of least resistance, and that summarize the event, the movie or the play. Based, as we say, in the innate ability that every human being has to draw inferences, inferring meanings and select the most relevant information, we will discuss the title of the latest novel by
\end{abstract}

\footnotetext{
* Author's address:

Departament de Filologies Romàniques

Universitat Rovira i Virgili

Av. Catalunya 35, 43002 Tarragona, Spain

E-mail josefa.rodriguez@urv.cat
} 
Marina Mayoral, wishes to see, after reading the book, whether or not it meets the expectations we had wrought.

Keywords: Name, title, Deseos, Marina Mayoral.

Resumen. El proceso de comunicación humana se caracteriza por el conjunto de actividades racionales que se llevan a cabo y que permiten que podamos no solo obtener información del entorno a través de la percepción, sino inferir nuevos conocimientos a partir de otros ya adquiridos. Según la teoría de la relevancia, desde el momento en que recibimos un estímulo ostensivo de carácter lingüístico, la mente del destinatario pone en marcha de manera automática diferentes tipos de procesos, comenzando por el más mecánico de descodificación (proceso gramatical) y siguiendo por otros de naturaleza inferencial, desde la desambiguación y la asignación de referente hasta la identificación de la intención del emisor (proceso pragmático): la comprensión de un enunciado o un texto no depende solo del significado de su estructura superficial, sino de su significado interno, de lo implícito, en definitiva. De la misma manera, cuando leemos una novela, vemos una película o contemplamos un suceso, de acuerdo con el principio cognitivo de relevancia ( $\mathrm{PCR}$ ), la mente humana maximiza la relevancia; es decir, en el proceso global de comprensión, "selecciona" aquellos ítems más relevantes, los que siguen la ley del mínimo esfuerzo, y que resumen el suceso, la película o la obra. Basándonos en la capacidad innata que todo ser humano tiene de extraer deducciones, inferir significaciones y seleccionar lo más relevante de una información, procederemos a comentar el título de la última novela de Marina Mayoral, Deseos, para ver, una vez leída la obra, si cumple o no con la expectativas que nos habíamos forjado.

Palabras clave: Nombre, título, Deseos, Marina Mayoral.

\section{El Nombre}

El primer contacto que tiene el espectador con una obra se establece por medio del título. Este puede ser sugerente, atractivo, extraño, curioso, etc., pero siempre ha de ceñirse al contenido. Si se admite que existe una relación entre el título y el contenido de la obra, el título se convierte en un aspecto informativo que no puede desdeñarse, puesto que adelanta el tema de la obra y facilita la entrada al mundo posible de la escena (Julio 1996: 448).

Siempre se ha dicho que quien no tiene nombre no tiene existencia; al menos socialmente hablando, así es. 
Las palabras, los nombres, son el medio con que la comunidad se las entiende con el mundo, lo clasifica y lo interpreta. Necesitamos los nombres para distinguir una realidad de otra, para apoderarnos de los objetos; los nombres de las cosas son bienes transmitidos por nuestros antepasados, exactamente como los usos y costumbres, el derecho o la religión. Cuando vemos un objeto, se nos ocurre su nombre enseguida; cuando oímos una palabra, aparece en nuestra conciencia la cosa correspondiente. El nombre nos lleva a la cosa, y la cosa propicia el recorrido contrario.

También el nombre nos designa, nos identifica, da cuenta de nuestra identidad: a través de él podemos distinguir el conjunto de rasgos propios que caracterizan a un individuo frente a los demás.

Dice Porzig que la lingüística surgió cuando los hombres se preguntaron:

por qué las cosas se llaman como se llaman. Es decir, lo que causó asombro a los hombres no fue que las cosas en general tengan un nombre; quisieron saber por qué llevaban precisamente ese nombre (Porzig 1957: 15-16).

El nombre, como dicen algunos, no es lo de menos. Una historia muy interesante nos ayudará a entenderlo. El físico británico, Sir Roger Penrose, anunció hace más de cincuenta años que había descubierto lo que él mismo denominó, en un principio, "un objeto totalmente colapsado gravitatoriamente", y la cosa se quedó así, sin mayor interés para nadie. Algunos meses más tarde, él mismo le cambió el nombre a su descubrimiento por el de "agujeros negros". Agujero negro, para todos, ya denota algo más provocativo, intrigante, excitante incluso, conceptual y, lo que es más importante, creíble. A partir de ahí es cuando se le hizo más caso al Sr. Penrose. Por tanto, nos podemos preguntar: ¿tiene o no importancia el nombre que le des a una cosa?

El nombre ha jugado un importante papel en todas las culturas desde la antigüedad más remota. En los pueblos orientales, el nombre era mucho más que un distintivo: pretendía reflejar el carácter de la persona que lo llevaba, su naturaleza. Esta práctica persiste hoy en día en las culturas del lejano oriente, donde los nombres de la gente, en realidad, aluden a elementos distintivos.

De igual manera, en el Antiguo Testamento, Dios se revelaba con diferentes nombres: cada uno apuntaba a alguna de sus características más importantes. $\mathrm{Y}$ los nombres hebreos marcan un destino, como símbolo que son de una vocación y señal de una elección divina. 
Por otra parte, estas tradiciones recorren toda la Edad Media, impregnando la cultura occidental. Así, la escuela neoplatónica, que florece en los primeros siglos de la era cristiana, en síntesis con el judaísmo, compone los primeros elementos ideológicos que impregnarán todo el medievo y pasarán como herencia, por ejemplo, a los Siglos de Oro. En esa época es cuando Fray Luis de León, en su obra titulada De los nombres de Cristo, habla de él, diciendo que:

El nombre, si habemos de decirlo en pocas palabras, es una palabra breve que se substituye por aquello de quien se dice y se toma por ello mismo. O nombre es aquello mismo que se nombra, no en el ser real y verdadero que ello tiene, sino en el ser que da nuestra boca y entendimiento (Fray Luis de León 1991: 72).

\section{El Título}

No cabe la menor duda de que hablar de la importancia cultural del nombre nos lleva al título de una obra literaria, al de un artículo periodístico o, incluso, al de un espectáculo cualquiera.

Ante la presencia de un título, el lector se pregunta qué relación puede tener o si existe o no correspondencia con el contenido al que se refiere.

Si está bien elegido, el título debe contener información muy relevante acerca del contenido de la obra y orientar al posible lector. Las palabras que componen el título son claves, lo que significa que, según la terminología de la lingüística del texto, este debe ser la macroestructura del discurso, como también apunta Casado Velarde, para quien los títulos "son el lugar preferido para las opiniones implícitas: el resumen de todo titular [título] supone, exige una validación de lo que es importante, interesante o pertinente" (Casado Velarde 1983: 235).

Así pues, la función cognitiva y comunicativa del título hace que se generen en el lector diversas expectativas, una de las cuales será la más precisa y predecible, la que como señuelo despierte en él el deseo de "consumir" aquello bajo cuyo epígrafe se expande. En este sentido, el título constituye un reclamo para el lector; excita la atención y prepara el ánimo, despertando la curiosidad sobre lo que va a leer.

Y hemos de mencionar que, en efecto, en la mayoría de los casos, el título es la célula a partir de la cual se genera el posterior texto. 


\section{El Nombre en el Título "Deseos"}

Los escritores saben de la importancia de escoger el título adecuado para sus respectivas obras, saben lo importante que es que "llame la atención" del futuro (potencial) lector.

Un elemento importantísimo en la confección de este título es la economía de que hace gala. Su eficacia comunicativa está precisamente en concentrar en una palabra el tema de la obra.

En la composición de los títulos hay que tener muy en cuenta una serie de factores contextuales que, superpuestos a lo lingüístico, cumplen la función de jerarquizar, valorar y ordenar la materia informativa con la finalidad de generar expectativas de relevancia que permitan una interpretación acorde con el mensaje que el emisor quiere comunicar.

El espacio tan restringido que ocupa el título, y la necesaria vinculación con el contenido de la obra, es el objeto de una retórica específica, tanto desde el punto de vista gramatical como en lo que atañe al léxico.

Deseos, de Marina Mayoral, no puede ser más reducido, más concentrado: un único nombre, sin artículo, adjetivo o verbo que lo acompañe, es toda la información que ofrece la autora al principio de la novela.

En el título de Marina Mayoral apreciamos, por ejemplo, la omisión del verbo, aunque se puede deducir fácilmente por su contenido lingüístico o extralingüístico, una omisión que hace que nos encontremos con una construcción que sintácticamente no es una oración completa, sino una expresión nominalizada que funciona como nombre identificador o etiqueta. Sin embargo, se trata de una expresión nominalizada que, como veremos, contiene muchísima información.

La nominalización no ha de importarnos, en este caso concreto, para poder apreciar el valor del título, pues en la recuperación de la información "perdida", a causa de la omisión de elementos lingüísticos, acuden a la mente diversos mecanismos cognitivos y contextuales que conducen a que el receptor, a través de un proceso inferencial, elija el significado correcto.

Esta nominalización del título apunta directamente a lo que importa y, desde el punto de vista expresivo, como muy bien dice Loffler-Laurian, tiene la ventaja de que cuenta con mayor carga enfática: 
L'énonce nominal véhicule et transmet davantage de charge emphatique que l'énonce verbal. Il va droit au but, assène le prédicat sans préparation. L'énonce verbal ondule et, sauf un ordre particulier des termes, il a moins d'impact. L'une des raisons en est que l'élément nominal peut fonctionner isolé (c'est sa puissance), alors que l'élément verbal ne peut pas fonctionner sans un élément nominal (c'est son impuissance) (Loffler-Laurian 1975: 114).

Una carga enfática que es importantísima en este título concreto de Deseos, como veremos.

Deseos nos narra la historia de un día (en concreto el 12 de octubre de 1982, desde las 6:30 de la mañana hasta las 00:00 horas del día siguiente) en la vida de los habitantes de Brétema (población gallega inventada por la autora).

Al avanzar en su lectura, vamos conociendo las distintas relaciones que se establecen entre los habitantes de esa población (familiares, de amistad,...), sus pensamientos y, sobre todo, vamos conociendo sus más íntimos y secretos "deseos".

El primer personaje que aparece frente a nuestros ojos, al iniciar la lectura, es Dictino. Son las 6:30 de la mañana y se está despertando: "Dictino bosteza estirando los brazos" (Mayoral 2011: 11).

Dictino es quien nos presenta a los tres siguientes personajes de la novela: la doctora, Consu, que está en la ventana de su casa cuando él mira hacia la calle, y Héctor Monterroso, que "baja pausadamente desde lo alto de la cuesta" (Mayoral 2011: 11). Él deduce que viene de la casa de la ¿protagonista? de la novela, doña Constanza. Y así nos sigue enlazando al resto de los personajes que van a poblar las hojas de esta novela: recuerda a don Pedro Monterroso -fallecido ya, esposo de doña Constanza y abuelo de Héctor (Mayoral 2011: 13)-; a Amelia, su esposa (Mayoral 2011: 14); a las viejas de Silva (Mayoral 2011: 14); a Maruxa (Mayoral 2011: 15); a doña Blanca, la boticaria fallecida y amiga de su esposa (Mayoral 2011: 15); al médico Germán, su cuñado (Mayoral 2011: 15), o a Blanquita, su propia hija (Mayoral 2011: 17).

Pero este primer capítulo de la novela no solo es importante por la magistral presentación de algunos personajes que hace la autora, sino sobre todo porque ya aparecen en él datos muy significativos sobre su título. 
Es doña Constanza la primera que habla de ello al decirle a Dictino que "siempre hay algo que deseamos y que no conseguimos. Y hay que aceptarlo" (Mayoral 2011: 16), anunciándonos luego con conformidad que ella "lo que más deseaba en la vida, lo único que de verdad he deseado en la vida, no lo pude conseguir" (Mayoral 2011: 16). Y nosotros nos preguntamos: ¿es el hijo de don Pedro, Hermes, ya muerto? Ella, en el cementerio, cuando va a verlo, le llama amor: "Hola, amor" (Mayoral 2011: 194) y, más adelante, confiesa ante su tumba que él ha sido "lo que más he deseado en la vida. Fíjate que no digo 'el hombre que más he deseado'. Digo: lo que más, lo único que de verdad he deseado" (Mayoral 2011: 281).

Doña Constanza ha deseado algo a lo largo de su vida y reconoce no haberlo conseguido: "y yo sé bien lo que es desear algo que no vas a conseguir" (Mayoral 2011: 200).

A partir de aquí, la autora nos va a ir desvelando, con una maestría genial, los más íntimos deseos que tienen el resto de los habitantes de Brétema, al menos los más importantes, y también nos va a comentar si los han podido satisfacer o no.

El siguiente es Dictino, al que la misma doña Constanza pregunta abiertamente: "Y tú, Dictino, ¿has conseguido lo que más deseabas en la vida?" (Mayoral 2011: 16). Pero a Dictino le da vergüenza ("¿Es algo vergonzoso, Dictino? ¿Tienes un deseo del que te avergüenzas?" (Mayoral 2011: 17)) y da muchos rodeos hasta confesárselo: "[...] y me di cuenta de que eso era lo que yo deseaba, doña Constanza: que apareciera una mujer así y se me echase en los brazos, aunque después se fuese para siempre [...]. Una mujer maravillosa una vez en la vida" (Mayoral 2011: 21).

Dictino también le confiesa y reconoce a doña Constanza que, como el de ella, su deseo es irrealizable: "[...] mi deseo no se puede cumplir, porque lo que yo deseo [...] es un milagro, un sueño" (Mayoral 2011: 21). Sin embargo, el de Dictino, unas líneas más abajo, se nos explica que ha sido cumplido por doña Constanza (Mayoral 2011: 23) y se va a ir recordando a lo largo de la obra: "Te cumplió aquellas ganas que tenías desde que empezaste a mocear" (Mayoral 2011: 147).

El siguiente capítulo está dedicado a Consuelo, otro personaje importante de la obra. Consu, la doctora, sigue introduciéndonos personajes como Héctor (lo ve a la vez que Dictino), el canónigo, Germán, Arancha, Constanza..., y a Juanma, su esposo (Mayoral 2011: 26), a Miguel, el enfermero (Mayoral 
2011: 36)... Así, poco a poco, se presentan personajes que van introduciendo a otros y, en este entramado de relaciones, vamos a seguir descubriendo qué es lo que desea cada uno y si se le ha cumplido.

Amelia es una maestra que trabaja en la botica del pueblo y también tiene un deseo: "Te gusta complacerlo, te ha dado lo que más deseabas en la vida" (Mayoral 2011: 61) o "Tú me diste (dirigiéndose a Dictino) lo que yo más deseaba en el mundo" (Mayoral 2011: 324). Así, le comunica a Dictino, el elegido, lo que desea: tener un hijo ("Empezaste a hacer listas de posibles padres" (Mayoral 2011:70)), y se lo pide abiertamente: "No querías engañarlo, tenías que decirle que querías un hijo, explicarle qué era lo que más deseabas en la vida y qué parte le correspondía a él en aquel deseo" (Mayoral 2011: 77-78).

Y Dictino reconoce haber sido él el encargado de cumplir los deseos de Amelia: "Te dijo que lo que más deseaba en la vida era tener un hijo" (Mayoral 2011: 155). Y Blanquita, la hija, también lo intuye: "Quizá tú eres lo que tu madre ha deseado más en el mundo: un hijo" (Mayoral 2011: 53) o "tú cumpliste a Amelia su mayor deseo" (Mayoral 2011: 23), que era tener un hijo.

Otro personaje, Héctor, desea a Constanza: "Que te lleven arrastrado mientras proclamas a gritos que la quieres, que es la mujer de tu vida, que es lo único que de verdad has deseado en la vida" (Mayoral 2011: 346). Pero Constanza es la viuda de su abuelo Pedro, y ella conoce este deseo ("Héctor me deseaba con todas sus fuerzas" (Mayoral 2011: 199)). Constanza se lo cumple también, pues cuando al final de la novela Héctor va a pedirle matrimonio, ella acepta (Mayoral 2011: 350-351).

Blanquita, la hija fruto del deseo de Amelia, lo que más quiere a su vez es salir de Brétema. Ella tiene una carrera, ha vivido ya fuera de España y se ahoga en el pueblo: "Blanquita ya no es tan joven, debería casarse, tener hijos, pero se ahoga en Brétema" (Mayoral 2011: 289). Al final, decide marcharse, aunque haga daño a sus padres, y se lo comenta a su amiga Inés: "Se lo conté a mi padre, le dije que me gustaría irme, y él me ayudó a decírselo a mi madre" (Mayoral 2011: 315).

Consuelo, la doctora del pueblo, lo único que deseaba en la vida era casarse con Juanma: "(A Juanma muerto) Tú eres lo que más he deseado en el mundo, lo único que realmente he deseado, y no pude resistir la tentación" (Mayoral 2011: 326). Como era un poco fea, no pensaba que él se fijara en ella, pero 
una desgracia los une ("Y el día de la boda sentiste que habías alcanzado lo que más deseabas en la vida" (Mayoral 2011: 221)).

Con todo, hay que decir que este deseo, a la larga, será la ruina de Consuelo, pues, tras conseguir casarse con Juanma cuando él sufre un accidente y queda paralítico, él la trata muy mal: "Y te diste cuenta de que Juanma no te quería, no te había querido y no te iba a querer nunca" (Mayoral 2011: 222). Por eso ella se arrepiente de haber conseguido su deseo:

Lo único que he deseado siempre es estar a tu lado. Creí que eso me bastaría para ser feliz: estar a tu lado, lo creí de verdad [...]. Me equivoqué, Juanma [...]. Me has hecho muy desgraciada, y yo te he hecho muy desgraciado a ti (Mayoral 2011: 328).

Por último, Etelvina, la escritora del pueblo, lo que desea es tener un "hijo literario", escribir un libro: "No vas a tener hijos, no vas a plantar árboles que te sobrevivan. Lo que escribas, eso será tu huella [...]. Quieres que te recuerden cuando hayas desaparecido" (Mayoral 2011: 332). Ella es "la peor" de todas las mujeres Silva, y por eso desea ser escritora, para servir de algo. Por ello, durante toda la obra está deseando finalizar el libro y convertirse en una escritora conocida, para demostrar a las demás Silva que ella sí que vale para algo: "Vale, Etelvina de Silva, buscas la inmortalidad en la Literatura, un 'remedo de eternidad'. Otros lo buscan en el amor, o en los hijos, cada uno se defiende como puede" (Mayoral 2011: 335).

\section{Conclusiones}

Los títulos de las obras deberían ser el resumen de ellas, pues es la primera información que recibimos de la obra y, por tanto, lo que va a crear en nosotros la primera expectativa sobre ella. Dado que existe una estrecha relación entre el título de una obra y su contenido, el título se convierte en una fuente de datos que se han de tener en consideración.

Marina Mayoral, como no podía ser de otra manera, no nos ha decepcionado en la elección del título para su obra, un título que a primera vista es muy simple pero que es también muy llamativo y está cargado de sentido dentro de la novela. 


\section{Bibliografía}

1. Casado Velarde, M. (1983). Semiótica de los titulares: pautas para un análisis de los titulares periodísticos. In Garrido Gallardo, M.A., Teoría semiótica. Actas del Congreso Internacional sobre Semiótica e Hispanismo (pp. 235-242). Madrid: CSIC.

2. Fray Luis de León (1991). Obras completas castellanas de Fray Luis de León. Madrid: Biblioteca de autores cristianos.

3. Julio, M.T. (1996). La recepción dramática. Aplicación al teatro de Rojas Zorrilla. Kassel: Reichenberger.

4. Loffler-Laurian, A.M. (1975). Lexique et fonctions dans les titres de presse. Cahiers de Lexicologie. Revue Internacionale de Lexicologie et Lexicographie, 26(1): 110-124..

5. Mayoral, M. (2011. Deseos. Madrid: Alfaguara.

6. Porzig, W. (1974). El mundo maravilloso del lenguaje. Madrid: Gredos.

\section{Author's Biodata}

M. José Rodríguez Campillo es doctora en literatura española por la Universitat Rovira i Virgili. Actualmente es profesora en el Departament de Filologies Romániques de la URV. Es especialista en literatura española del siglo XVII. Su tesis doctoral sobre las Implicaturas en el teatro femenino de los Siglos de Oro constituye un claro ejemplo de la investigación desarrollada por la Dra. Campillo en la que se concede una importancia fundamental a la interdisciplinariedad. La utilización de métodos lingüísticos para el análisis literario es una constante en sus artículos publicados en revistas y volúmenes monográficos. Ha participado en numerosos congresos internacionales y ha organizado reuniones científicas en las que se pretende fomentar la visibilidad de la literatura escrita por mujeres. 